\title{
Correction to: Youth Anti-Racist Engagement: Conceptualization, Development, and Validation of an Anti-Racism Action Scale
}

\author{
Adriana Aldana $^{1}\left[{ }^{[} \cdot\right.$ Josefina Bañales $^{2} \cdot$ Katie Richards-Schuster ${ }^{1,3}$
}

Published online: 21 February 2022

○) Springer Nature Switzerland AG 2022

\section{Correction to: Adolescent Research Review (2019) 4:369-381 \\ https://doi.org/10.1007/s40894-019-00113-1}

The original version of this article unfortunately contained a mistake. A sentence under the heading 'Study 2: Confirmatory Factor Analysis' read as 'However, two items from the Interpersonal Action scale (Action 4 and Action 5) loaded below 0.40 and thus were removed from the scale', the sentence should have read as 'However, two items from the Interpersonal Action scale (Action 6 and Action 7) loaded below 0.40 and thus were removed from the scale'.

The original article has been corrected.
The original article can be found online at https://doi.org/10.1007/ s40894-019-00113-1.

Adriana Aldana

aaldana@csudh.edu

Josefina Bañales

jbanales@umich.edu

Katie Richards-Schuster

kers@umich.edu

1 Department of Social Work, California State University Dominguez Hill, 1000 E. Victoria Street, Carson, CA 90747, USA

2 Department of Psychology, University of Michigan, 530 Church Street, Ann Arbor, MI 48109, USA

3 School of Social Work, University of Michigan, 1080 S. State Street, Ann Arbor, MI 48109, USA
Publisher's Note Springer Nature remains neutral with regard to jurisdictional claims in published maps and institutional affiliations. 